\title{
Effect of vitamin D on Becker muscular dystrophy: A review
}

\author{
Shaymaa H Alasady \\ Iraq Ministry of Health, Babylon, Iraq \\ *For correspondence: Email: shaymaaalasady@yahoo.com; Tel: (+964)-7811037517
}

Sent for review: 24 March 2020

Revised accepted: 16 November 2020

\begin{abstract}
The correlation between Becker muscular dystrophy (BMD) and vitamin D has long been known, since vitamin $D$ controls bone turnover which occurs in this disease. Thus, vitamin $D$ is beneficial to some extent to BMD patients due to the fact that it has long been known to play an important part in bone metabolism. According to recent studies which suggest association between vitamin $D$ and multiple diseases involving multiple organs, vitamin $D$ may alleviate the pathophysiology of $B M D$. This review focuses on the benefits of vitamin $D$ to BMD patients through alleviation of the pathophysiology and complications of the disease.
\end{abstract}

Keywords: Becker muscular dystrophy, Cardiomyopathy, Vitamin D

\begin{abstract}
This is an Open Access article that uses a fund-ing model which does not charge readers or their institutions for access and distributed under the terms of the Creative Commons Attribution License (http://creativecommons.org/licenses/by/4.0) and the Budapest Open Access Initiative (http://www.budapestopenaccessinitiative.org/read), which permit unrestricted use, distribution, and reproduction in any medium, provided the original work is properly credited.

Tropical Journal of Pharmaceutical Research is indexed by Science Citation Index (SciSearch), Scopus, International Pharmaceutical Abstract, Chemical Abstracts, Embase, Index Copernicus, EBSCO, African Index Medicus, JournalSeek, Journal Citation Reports/Science Edition, Directory of Open Access Journals (DOAJ), African Journal Online, Bioline International, Open-J-Gate and Pharmacy Abstracts
\end{abstract}

\section{INTRODUCTION}

Becker muscular dystrophy (BMD) is a genetic disorder caused by a mutation in dystrophin gene, resulting in synthesis of a defective dystrophin protein in the muscle. This disease is named after the German doctor, Peter Email Becker, who first described this variant of BMD [1-3]. Dystrophin performs a major structural role because it links the internal cytoskeleton to the extracellular matrix. The $\mathrm{N}$-terminal amino acid of dystrophin binds to actin, while the C-terminal amino acid binds to dystrophin-associated protein complex (DAPC) which consists of dystroglycans, sarcoglycans, integrins and caveolins. Dystrophin-associated protein complex (DAPC) is destabilized when dystrophin is absent, leading to diminished levels of the member protein. This in turn leads to progressive fiber damage and membrane leakage [4-6]. The muscles affected by this disease are skeletal muscle, cardiac muscle and respiratory muscle. The decline in cardiac muscle in these patients may surpass decline in skeletal muscle, and death from cardiomyopathy often occurs before the age of 60 [7-9]. The role of vitamin $D$ in bone metabolism has for long been recognized. However, recent studies have suggested the involvement of vitamin $D$ in many skeletal diseases.

This review was carried out to summarize the pathophysiology of BMD and effect of vitamin D on the disease, based on recent studies. 


\section{Pathophysiology of dystrophin-deficient skeletal muscle}

Muscle damage is the first step in the pathophysiology of dystrophin-deficient muscle which finally leads to pathological processes such as loss of calcium homeostasis, chronic inflammatory response, and ultimately fibrosis. Thus, two defects occur in dystrophin-deficient muscle which may lead to muscle damage: fragility and leakiness of cell membrane (due to a defect in dystrophin gene) which render the muscle highly susceptible to mechanical stress and ischemia [7]. Three different isoforms of nitric oxide synthase (NOS) are generated by three genes in skeletal muscle. These genes are neuronal NOS (nNOS or NOS1 which is the predominant form of NOS in skeletal muscle fibers and an isoenzyme form of nNOS; inducible NOS (iNOS or NOS2) which is present in small amounts in healthy muscle tissue, but in muscular dystrophy, there are increases in iNOS in skeletal muscle (SM) as a result of presence of inflammatory cells rich in the isoenzyme; and endothelial NOS (eNO or NOS3). In SM, eNOS is derived mostly from cells of the endothelium.

Ischemia in dystrophin-deficient skeletal muscle is caused by several factors viz:

(a) Deficiency of nNOS: The nitric oxide (NO) produced by nNOS is very important for increasing local blood flow to meet metabolic load of contracting muscle, especially during exercise. Thus, lack of nNOS leads to functional ischemia $[5,10,11]$.

(b) Deficiency of eNOS: As mentioned previously, SM eNOS is present mainly in vasculature endothelium. The NO produced by eNOS is necessary for regulation of vascular tone and blood flow. Consequently, any defect in NO production by this enzyme may result in ischemia. Indeed, it has been reported that eNOS level is reduced in dystrophin-deficient patients [12]. After muscle damage, a number of pathological processes occur which finally lead to fibrosis as a result of increased calcium level in dystrophin-deficient muscle due to leakiness of cell membranes, an important factor in the pathophysiology of cell death $[7,13]$. The increased calcium levels induce proteolysis due to activation of calcium-dependent proteases such as skeletal muscle-specific calpains and activation of calcium channel, ultimately leading to muscle degeneration $[7,14]$. Moreover, chronic inflammation results from oxidative damage which occurs as a consequence of impaired calcium homeostasis [15] and inflammation/ fibrosis which occur due to continuous muscle degeneration and damage, as in muscular dystrophy. Chronic inflammation ultimately leads to fibrotic lesions characterized by massive deposition of collagen, resulting in permanent scar formation that impairs tissue function. Injury to muscles lacking dystrophin provokes a 'cytokine storm'. Cytokines [e.g. tumor necrosis factor alpha (TNFa), interleukin (IL)-1 and IL-4) are major mediators of inflammatory responses involved in tissue lesions $[13,16,17]$. These damages include pathophysiological changes that can occur in dystrophin-deficient muscle (skeletal muscle) which ultimately decrease the strength of the muscle. The pathophysiological processes involved in dystrophin deficiency are summarized in Figure 1.

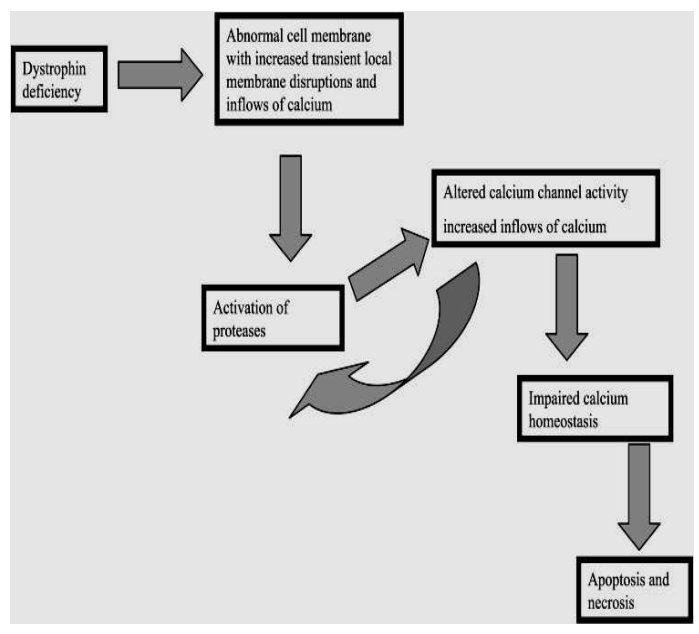

Figure 1: Pathophysiology of dystrophin deficiency

Immune cells involved in inflammation of dystrophin deficient skeletal muscle

The immune cells involved in inflammation in skeletal muscle in BMD are:

Macrophages: The key cells associated with damaged muscle tissue are tissue-resident macrophages and blood-derived monocytes which arise from invasion of the injury site (they also differentiate into macrophages). These macrophages perform the function of removing muscle tissue debris, apart from regulating muscle regrowth through cytokine release $[18,19]$. There are two types of macrophages in regenerating muscles after injury, and they are involved in opposing functions i.e. proinflammatory and anti-inflammatory macrophages. The pro-inflammatory type comprise macrophages or classically activated (M1) macrophages which are implicated in acute inflammatory processes due to exposure to Thelper1 cytokines (INF- $\mathrm{y}$ and TNFa) and LPS. The M1 macrophages appear in early stages of 
muscle injury with recruited monocytes, and are involved in antigen presentation, phagocytosis of dead tissue components, and secretion of inflammation-inducing cytokines (tumor necrosis factor- $\alpha$ and interleukins). Moreover, M1 macrophages secrete iNOS which catalyzes the conversion of L-arginine substrate to NO used for destroying pathogenic organisms. In contrast, activated M2 macrophages consist of sub-types which perform varied functions. The M2a subtype is linked to tissue repair and fibrotic lesions, while the M2c sub-type is thought to inhibit inflammation since it suppresses M1 macrophages. In addition, M2c enhances the viability of cells outside the bone marrow. Therefore, M2 macrophages are associated with the initial phases of muscle damage, prior to presence of M2c sub-type, while the M2a subtype dominates at the later phases [16].

$T$ lymphocytes: These are the other cells in the immune system which are involved in muscle repair and fibrosis. They can differentiate into different functional types: CD4+ $\mathrm{T}$ helper-1 cells produce interferon- $\mathrm{Y}, \mathrm{TNF} \alpha, \mathrm{IL}-12$ and IL-20 which enhance cell-mediated immunity. These cytokines exert fibrosis-suppressing effects. On the hand, CD4+ T helper (Th)2 cells secrete IL-4, IL-5, IL-6 and IL-13 which induce fibrosis. The Th1 and Th2 cytokines are mutually antagonistic in their functions. Changes in this mutual relationship are reflected in either pathogenesis of fibrosis or suppression of same [20]. In addition, the other inflammatory cells involved in dystrophic muscle fiber wasting are mast cells, eosinophils, and neutrophils. However, the role of these cells in BMD is not clear, although research data indicate that they are significant factors in pathogenesis of the disease [21].

\section{Pathophysiology of dystrophin-deficient cardiac muscle}

In addition to skeletal muscle involvement in BMD, myocardial involvement also occurs, resulting in dilated cardiomyopathy (DCM). Studies have shown DCM, a progressive disease linked to heart failure and ventricular arrhythmias, results in high degree of morbidity and mortality $[22,23]$. The main pathophysiological changes involved in cardiac muscle fibrosis are similar to some extent to what occurs in skeletal muscle. Impairments in membrane stability, as well as impaired resistance to mechanical stress and ischemia which nearly resemble what occurs in skeletal muscle due to dysfunctional dystrophin protein, lead to cardiomyocyte damage. These changes lead to a sequence of events which result in fibrosis. The pro-fibrotic changes are increased calcium influx as a result of fragility and susceptibility of the sarcolemma to damage from muscle contractions, which finally leads to death of cardiomyocytes; and membrane-destructive proteolysis due to calcium-induced activation of calpains, a group of proteases, resulting even in more calcium influx. Sustained $\mathrm{Ca}^{2+}$ overload results in cardiomyocyte necrosis [24-26]. Moreover, it leads to oxidative damage due to impairment of mitochondrial function and raised levels of damaging free radicals, both of which ultimately lead to cell death [15]. When cardiomyocytes are damaged, inflammation occurs due to migration of macrophages to remove lesioned cells and rubble. This results in fibrosis due to invasion of the damaged area by fibroblasts which then form a scar tissue. Fibrosis results in inflexible scar tissue, thereby decreasing the contractility of heart muscle. The fibrotic region gradually stretches, becomes thinner and loses contractility, leading to dilated cardiomyopathy $[16,24]$.

\section{Vitamin D}

Vitamin $D$ is a fat-soluble vitamin that exists in two forms: ergocalciferol or vitamin D2 and cholecalciferol or vitamin D3. Vitamin D2 is present in plants and some fish, while vitamin D3 is synthesized in the skin from 7dehydrocholesterol on exposure to sunlight (ultraviolet B rays) [27-29]. Vitamin D in its native form is not biologically active. Vitamin $D$ from diet (ergocalciferol) and skin (cholecalciferol) are transported in the blood by circulating vitamin Dbinding globulin to the liver where it is converted to 25-OHvitamin D (25-OHD), the main circulating metabolite of vitamin $D$ which has low biological activity. In the kidneys, 25-OHD is hydroxylated by the enzyme $1 \alpha$-hydroxylase to 1,25-diOH vitamin $\mathrm{D}[1,25(\mathrm{OH}) 2 \mathrm{D}]$, the active form of the vitamin [30-32].

\section{Functions of vitamin D}

Vitamin $D$ is important for maintenance of adequate serum levels of calcium and phosphorus necessary for formation and sustenance of strong bones [33]. The binding of $1,25-(\mathrm{OH}) 2 \mathrm{D}$ to its receptor (VDR) enhances the absorption of $\mathrm{Ca}$ in the intestine up to $40 \%$, and enhances that of phosphorus to about $80 \%$ [34]. Vitamin $D$ receptor (VDR) is present in osteoblasts. Vitamin $D$ deficiency impacts the skeletal muscle, and results either in rickets or osteomalacia, depending on age [35-37]. The discovery of the presence of VDR in various other sites such as cardiomyocytes, pancreas, immune cells, brain and other sites suggests that 
the vitamin has effects on other systems apart from musculoskeletal system [38-40].

\section{Vitamin D and Becker muscular dystrophy}

Vitamin D may play a role in mitigating BMD in skeletal and cardiac muscles. As mentioned previously, ischemia is one of the pathophysiological features of BMD in skeletal and cardiac muscles. Ischemia arises from lack of eNOS. The endothelial cells contain VDR which express 1-alpha-hydroxylase that enables the endothelial cells carry out the conversion of $25-\mathrm{OHD}$ to $1,25(\mathrm{OH}) 2 \mathrm{D}$ which controls the expression of NOS in endothelial cells, thereby enhancing the production of NO [41]. Thus, administration of vitamin $\mathrm{D}$ to BMD patients may alleviate ischemia which occurs in skeletal and cardiac muscles, especially in patients suffering from vitamin $D$ deficiency. Moreover, vitamin $D$ may mitigate oxidative damage that occurs in $B M D$ due to the fact vitamin $D$ suppresses the generation of superoxide anion, thereby inhibiting ROS and oxidative stress $[42,43]$

In chronic inflammation which leads to fibrosis, an important step in the pathophysiology of BMD in skeletal and cardiac muscles, the expressions of cytochrome p450 27B1 and VDR genes by macrophages and $\mathrm{T}$ lymphocytes are markedly upregulated. This suggests that vitamin $D$ may target the immune/inflammation system via regulation of expressions inflammatory cytokines and suppression of pro-inflammatory cells [44, 34]. Thus, vitamin $D$ may be beneficial to BMD patients.

\section{CONCLUDING REMARKS}

There is need for further studies on the mitigating influence of vitamin $D$ on BMD. Although recent studies indicate that vitamin $D$ is critical in the pathophysiology of other diseases beyond its critical function in maintenance of calcium homeostasis, there is still limited knowledge about the relationship between vitamin $D$ and BMD. Thus, further studies are needed to get more detailed information on how vitamin $D$ may help BMD patients to maintain muscle mass and strength and decrease cardiac complications associated with the disease.

\section{DECLARATIONS}

\section{Acknowledgement}

I thank Doaa Hamed Alasady, Mohammed Hashem Alhussainy and Fouad Al-Kaim who provided general support for this work.

\section{Conflict of interest}

No conflict of interest is associated with this work.

\section{Contribution of authors}

I declare that this work was done by the author named in this article and all liabilities pertaining to claims relating to the content of this article will be borne by the authors. The author read and approved the final manuscript.

\section{Open Access}

This is an Open Access article that uses a funding model which does not charge readers or their institutions for access and distributed under the terms of the Creative Commons Attribution License (http://creativecommons.org/licenses/by/ 4.0) and the Budapest Open Access Initiative (http://www.budapestopenaccessinitiative.org/rea d), which permit unrestricted use, distribution, and reproduction in any medium, provided the original work is properly credited.

\section{REFERENCES}

1. Zeidman LA, Kondziella D. Peter Becker and His Nazi Past: The Man Behind Becker Muscular Dystrophy and Becker Myotonia. J Child Neurol 2013; 00(0): 1-6.

2. Okubo M, Minami N, Goto K, Goto Y, Noguchi S, Mitsuhashi S, Nishino I. Genetic diagnosis of Duchenne/Becker muscular dystrophy using nextgeneration sequencing: validation analysis of $D M D$ mutations. J Hum Genet 2016; 61: 483-489.

3. Bello L, Campadello P, Barp A, Fanin M, Semplicin C, Sorarù G, Caumo L, Calore Ch, Angelini C, Pegoraro E. Functional changes in Becker muscular dystrophy: implications for clinical trials in dystrophinopathies. J Sci Rep 2016; 6: 1-12.

4. Johnson EK, Zhang L, Adams ME, Phillips A, Freitas MA, Froehner SC, Green-Church KB, Montanaro $F$. Proteomic Analysis Reveals New Cardiac-Specific Dystrophin-Associated Proteins. J PLOS 2017; 7:1-12.

5. Ehmsen J, Poon E, Davies K. The dystrophin associated Protein complex. J Cell Sci 2002; 115:2801-2803.

6. Nowak KJ, Davies KE. Duchenne muscular dystrophy and dystrophin: pathogenesis and opportunities for treatment. J Europ mol biol organ 2004; 5:872-876.

7. Blake DJ, Weir A, Newey SE, Davies KE. Function and Genetics of Dystrophin and Dystrophin-Related Proteins in Muscle. J Physiol Rev 2002;82: 291-329.

8. Finsterer J, Stöllberger C. Cardiac involvement in Becker muscular dystrophy. J Can J Cardiol 2008;24: 786-792.

9. Thomas JD. Functional muscle ischemia in Duchenne and Becker muscular dystrophy. J front physiol 2013; 4:1-6.

Trop J Pharm Res, December 2020; 19(12): 2694 
10. Allen DG, Whitehead NP, Froehner SC. Absence of dystrophin disrupts skeletal muscle signaling: roles of $\mathrm{Ca}+2$, reactive oxygen species, and nitric oxide in the development of muscular. J Physiol Rev 2016; 96:253305.

11. Garbincius JF, Michele DE. Dystrophin-glycoprotein complex regulates muscle nitric oxide production through mechanoregulation of AMPK signaling. J PNAS 2015;112: 13663-13668.

12. Palladino M, Gatto I, Neri V, Straino S, Smith RC, Silver M, Gaetani E, Marcantoni M, Giarretta I, Stigliano E et al. Angiogenic Impairment of the Vascular Endothelium A Novel Mechanism and Potential Therapeutic Target in Muscular Dystrophy. J Arterioscler Thromb Vasc Biol 2013;33: 2867-2876.

13. Porter JD, Khanna S, Kaminski HJ, Rao JS, Merriam AP, Richmonds CR, Leahy P, Li J, Guo W, Andrade FH. A chronic inflammatory response dominates the skeletal muscle molecular signature in dystrophin-deficient $m d x$ mice. J hum mol genet 2002; 11: 263-272

14. Culligan KG, Ohlendieck K. Abnormal Calcium Handling in Muscular Dystrophy. J Basic Appl Myol 2002; 12: 147-157.

15. Kelly-Worden M, Thomas E. Mitochondrial Dysfunction in Duchenne Muscular Dystrophy. Open J Endocr Metab Dis 2014; 4 :211-218.

16. Mann CJ, Perdiguero E, Kharraz Y, Aguilar S, Pessina P, Serrano LA, Muñoz-Cánoves $P$. Aberrant repair and fibrosis development in skeletal muscle. Skelet Muscle 2011; 1:1-20.

17. Zhou L, Lu H. Targeting Fibrosis in Duchenne Muscular Dystrophy. J Neuropathol Exp Neurol 2010; 69: $771-$ 776.

18. Arnold L, Perrin $H$, de Chanvielle $C B$, Saclier $M$, Hermand P, Poupel L, Guyon E, Licata F, Carpentier W, Vilar $J$ et al. CX3CR1 deficiency promotes muscle repair and regeneration by enhancing macrophage ApoE production. J Nat Commun 2015; 6:1-12.

19. Kawanishi N, Mizokami T, Niihara H, Yada K, Suzuki K. Macrophage depletion by clodronate liposome attenuates muscle injury and inflammation following exhaustive exercise. J Biochem and Biophys Rep 2016; 5: 146-151.

20. Kharraz Y, Guerra J, Mann CJ, Serrano AL, MuñozCánoves P. Macrophage Plasticity and the Role of Inflammation in Skeletal Muscle Repair. J Mediat Inflamm 2013; 10: 1-9.

21. Evans NP, Misyak SA, Robertson JL, Riera JB, Grange $R W$. Immune mediated mechanisms potentially regulate the disease time course of Duchenne muscular dystrophy and provide targets for therapeutic intervention. J Phys Med Rehabil 2009; 1: 755-768.

22. Mastumura K, Nonaka I, Tomè MS, Arahata K, Collin H, Leturcq F, Rècan D, Kaplan JC, Fardeau M, Campbell KP. Mild Deficiency of Dystrophin-associated Proteins in Becker Muscular Dystrophy Patients Having In-Frame Deletions in the Rod Domain of Dystrophin. Am J Hum Genet 1993; 53: 409-416.
23. Yilmaz A, Gdynia HJ, Baccouche $H$, Mahrholdt $H$, Meinhardt G, Basso C, Thiene G, Sperfeld AD, Ludolph $A C$, Sechtem U. Cardiac involvement in patients with Becker muscular dystrophy: new diagnostic and pathophysiological insights by a CMR approach. J Cardiovasc Magn Reson2008; 10: 1-12.

24. Kaspar RW, Allen HD, Montanaro F. Current understanding and management of dilated cardiomyopathy in Duchenne and Becker muscular dystrophy. J Am Acad Nurse Pract 2009; 21: 241-249.

25. Verhaert D, Richards K, Rafael Fortney JA, Raman SV. Cardiac Involvement in Patients with Muscular Dystrophies: Magnetic Resonance Imaging Phenotype and Genotypic Considerations. J Circ Cardiovasc Imaging 2011; 4: 67-76.

26. HO R, Nguyen M, Mather P. Cardiomyopathy in becker muscular dystrophy: Overview. World J Cardiol 2016; 8: 356-361.

27. Al-Shoumer K AS, Al-Essa TM. Is there a relationship between vitamin $D$ with insulin resistance and diabetes mellitus? World J Diabetes 2015; 6: 1057-1064.

28. Teresa K, Amy G, Jackie $R$, Jennie $H$ and Sarina $S$. Vitamin D: An Evidence-Based Review. JABFM 2009, 22: 698-706.

29. Barry MJ, Vries ED, Giovannucci E, Lehmann B, Møller H, Peto J, Walter S. Vitamin D and Cancer. IARC 2008; 5: 1-210.

30. Chung M, Balk EM, Brende M, Lau J, Lee J, Lichtenstein A, Patel A, Raman G, Tatsioni A, Terasawa T, Trikalinos T. Vitamin $D$ and Calcium: A Systematic Review of Health Outcomes. AHRQ 2007: 1-342.

31. Zittermann A. Vitamin $D$ in preventive medicine: are we ignoring the evidence? Br J Nutr 2003; 89:552-572.

32. Bikle DD. Vitamin D Metabolism, Mechanism of Action, and Clinical Applications. Chem \& Biol 2014; 21: 319329

33. Zhang R, Naughton DP. Vitamin $D$ in health and disease: Current perspectives. Nutr J 2010; 9: 1-13.

34. Holick MF. Vitamin D Deficiency. N Engl J Med 2007; 8:357-266.

35. Lam NN. The Role of Vitamin D Receptor in Osteoblasts and Bone Mineralisation. The University of Adelaide; 2012: 1-167.

36. Ohtera K, Ishii S, Matsuyama T. Influence of the vitamin $D$ receptor alleles on human osteoblast-like cells. J Bone Joint Surg 2000; 82: 8-134.

37. Kienreich K, Grübler M, Tomaschitz A, Schmid J, Verheyen N, Rutters F, Dekker JM, Pilz S. Vitamin D, arterial hypertension \& cerebrovascular disease. Indian J Med Res2013; 137: 669-679.

38. Kienreich K, Tomaschitz A, Verheyen $N$, Pieber $T$, Gaksch M, Grübler RM, Pilz S. Vitamin $D$ and Cardiovascular Disease. J Nutr 2013; 5: 3005-3021.

39. Amit V, Vandana K, Neeraj K, Preeti K. Vitamin $D$ and Diabetes: A New Horizon. Acta Medica Int 2014; 1: 134139.

40. Eyles DW, Smith S, Robert K, Hewison M, McGrath JJ. Distribution of the Vitamin $D$ receptor and 1a-

Trop J Pharm Res, December 2020; 19(12): 2695 
hydroxylase in human brain. J Chem Neuroanat 2005; 29: 21-30.

41. Menezes AR, Lamb MC, Lavie CJ, DiNicolantonio JJ. Vitamin $D$ and atherosclerosis. J. Curr Opin 2014; 29: 571-577.

42. Uberti F, Lattuada D, Morsanuto V, Nava U, Bolis G, Vacca G, Squarzanti D F, Cisari C, Molinari C. Vitamin $D$ Protects Human Endothelial Cells from Oxidative Stress Through the Autophagic and Survival Pathways. J Clin Endocrinol Metab 2014; 99: 1367-1374.
43. Tarcin O, Yavuz D G, Ozben B, Telli A, Velioglu O, Yuksel M, Tobrak A, Yazici D, Sancak S, Deyneli O, Akalin S. Effect of Vitamin $D$ Deficiency and Replacement on Endothelial Function in Asymptomatic Subjects. J. Clin Endocrinol Metab 2009; 94: 40234030.

44. Yin $K$, Agrawal DK. Vitamin $D$ and inflammatory diseases. J Inflamm Res 2014; 7: 69-87. 